\title{
Applications of neutron scattering in investigations of adsorption processes in porous materials
}

\author{
John D.F.RAMSAY* \\ CNRS, Institut de Recherches sur la Catalyse, 2, avenue Albert Einstein, 69626 \\ Villeurbanne, France
}

\begin{abstract}
Neutron scattering techniques can provide direct information on the porous microstructure of adsorbents and the mechanisms of adsorption processes. The application of incoherent and coherent scattering in investigations of the structure and adsorption of water in two model systems are considered. These include mesoporous silica gels, prepared by sol-gel techniques and microporous carbon fibres. It is shown that the structure and diffusive motion of water is markedly perturbed when the pore size approaches the micropore range $(<2 n m)$. Furthermore small angle neutron scattering can provide direct insight into the mechanisms of multilayer formation and capillary condensation in mesoporous solids. Information on the shape and preferential orientation of pores in carbon fibres has also been obtained. The fractal nature of the surfaces in these microporous materials is also discussed.
\end{abstract}

\section{INTRODUCTION}

An understanding of adsorption processes in porous materials is of fundamental importance in processes such as gas storage and separation, chromatography and catalysis. Neutron scattering is a powerful technique which can provide direct information on the structure and dynamics of adsorbed molecules and in particular the role and influence of the adsorbent microstructure (porosity, surface characteristics) on theses properties (refs. 1-5).

Here the application of several neutron scattering techniques will be reviewed. These include incoherent quasielastic and inelastic scattering (IQENS), neutron diffraction, and small angle neutron scattering (SANS). These techniques will be illustrated with reference to two model adsorbent systems.

Firstly the adsorption of water in porous oxide gels will be considered. Such systems can be prepared with controlled porous properties by sol-gel techniques (ref. 10). It will be shown by IQENS, diffraction and SANS that the pore size has a marked effect on the dynamics (translational, rotational diffusion) and hydrogen bond structure of water, particularly when the molecules are confined in micropores.

Similar effects of specific surface interaction and molecular confinement of water are illustrated in recent investigations of microporous carbon fibres. Here SANS and diffraction techniques have been applied to explore the effects of orientation of the slit-shaped micropores along the axes of the carbon fibres.

We will also illustrate the novel application of SANS to follow the process of adsorption of water in microporous and mesoporous oxide gels. Such measurements provide a direct insight into the mechanism of capillary condensation in porous solids with a well defined pore geometry.

\section{TYPES OF NEUTRON SCATTERING PROCESS}

There are two types of scattering process which can be used to investigate adsorption processes :

(a) incoherent scattering

(b) coherent scattering

The application of incoherent scattering is particularly applicable to the study of molecules containing hydrogen $\left({ }^{1} \mathrm{H}\right.$ ) atoms due to its very large incoherent scattering cross-section (cf. Table 1 ).

\footnotetext{
* The manuscript was received in the editorial office of this journal before the symposium. However, it was not presented because of the lecturer's inability to attend the meeting due to unavoidable circumstances.
} 
TABLE 1. Values of incoherent cross-section, $\sigma_{\text {inc }}$ for different elements

\begin{tabular}{c|c|c|c|c|c}
\hline Atom & H & D & O & C & Si \\
$\sigma_{\text {inc } 1024 / \mathrm{cm}^{2}}$ & 79.7 & 2.0 & 0.0 & 0.0 & 0.0 \\
\hline
\end{tabular}

\subsection{Incoherent scattering}

Incoherent scattering can be used to study the diffusion and quantised librational and vibrational modes of adsorbed molecules. These result in a change of energy of the scattered neutron (refs. 7.8).

For example for water, diffusive motions (translational, rotational) correspond to energy changes in the range $\leq 1 \mathrm{meV}$ (QUASIELASTIC) and librational modes arise in the range up to $\approx 100 \mathrm{meV}$ (INELASTIC). These ranges are illustrated in Figure 1.

The librational modes are very sensitive to hydrogen bonding and reflect perturbations in the structure of water confined in small pores and at surfaces (refs. 7-11).

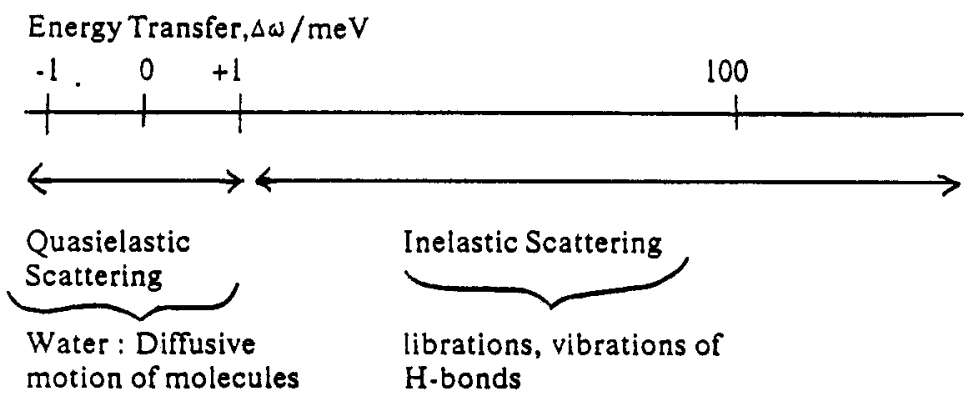

Fig 1 : Energy transfer range,swfor quasielastic and inelastic scattering of water corresponding to diffusive and coupled intermolecular modes due to hydrogen bonding respectively.

\subsection{Coherent scattering}

Coherent scattering has its counterpart in X-ray scattering which is an elastic scattering process (no energy change) although the scattering cross sections of atoms are different (ref. 12). These can be defined as coherent scattering lengths $b_{c o h}$.

Values of $b_{c o h}$, can vary for different isotopes of the same element.

This is particularly important for hydrogen $\left({ }_{\mathrm{H}}^{\mathrm{H}} ;{ }^{2} \mathrm{H}\right)$ see Table 2 and allows the important techniques of contrast variation to be exploited, as will be demonstrated.

TABLE 2. Values of coherent scattering lengths, $b_{c o h}$ for selected elements

\begin{tabular}{c|c|c|c|c|c|c}
\hline Element & $\mathrm{H}$ & $\mathrm{D}$ & $\mathrm{O}$ & $\mathrm{C}$ & $\mathrm{Si}$ & $\mathrm{Ti}$ \\
$1012 \mathrm{~b}_{\mathrm{coh}^{\prime}} \mathrm{cm}$ & -0.374 & 0.667 & 0.58 & 0.665 & 0.42 & .0 .34 \\
\hline
\end{tabular}

We can distinguish two different types of experiment involving coherent scattering :
(a) diffraction
(b) small angle neutron scattering (SANS)

\subsubsection{Small angle neutron scattering}

This is a very powerful technique for obtaining information about the properties of porous solids (refs. 13.15). Thus information is obtained from measurements of the scattered intensity as a function of angle, $2 \theta$ or $Q$, where $Q=4 \pi \sin \theta / \lambda$. The wavelength of monochromated neutrons, $\lambda$, is generally in a range 5 to $15 \AA$. The appropriate angular range for obtaining structural details of objects with a dimension, $d$, is given by $d \approx \lambda /$ $2 \theta$.

We will illustrate the application of both neutron diffraction and SANS here with reference to different experiments made with two model adsorbents - mesoporous silica gels and microporous carbon fibres. 


\section{INELASTIC AND QUASIELASTIC SCATTERING OF WATER IN POROUS SILICA GELS}

The effect of temperature on the inelastic scattering and quasielastic scattering of water adsorbed in silica gel containing small mesopores $(=2-3 \mathrm{mn}$ ) is markedly different from that in the bulk (see figures 2 and 3 ).

We note that the breadth of the quasielastic peaks (figure 3) decreases as the temperature is reduced from $\approx$ 300 to $200 \mathrm{~K}$ indicating a reduction in the rate of diffusion. However the water remains in a supercooled liquid state and cannot crystallize to give an ice phase.

Cooling also results in marked changes in the inelastic spectrum (see figure 2) corresponding to quantised rotations and librational modes. These are again different from bulk ice and indicate a supercooled liquid or vitreous state.

It can be shown that perturbation in the structure of water becomes pronounced when the pore size is $<5 \mathrm{~nm}$.

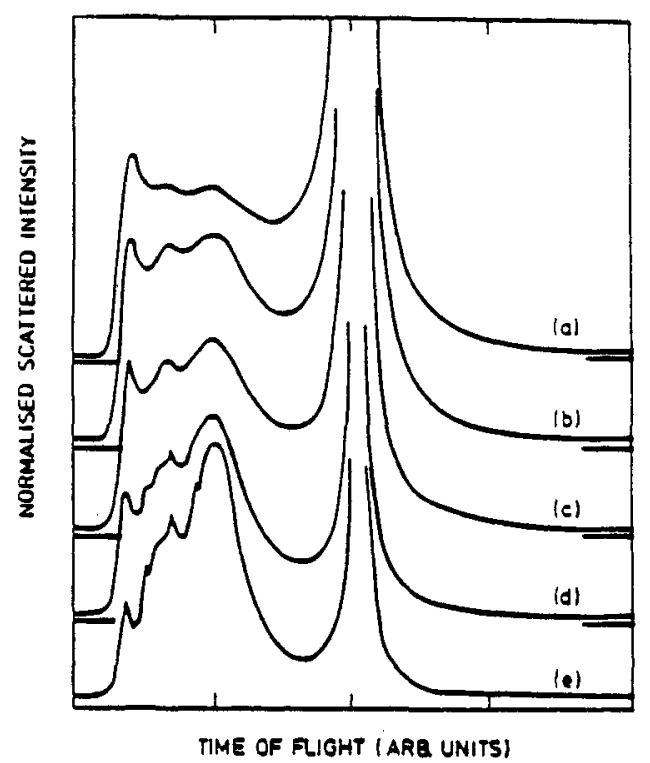

Fig.2:Time-of-flight spectra of water adsorbed in porous silica $\left(0.27 \mathrm{~g}\right.$ of $\left.\mathrm{H}_{2} \mathrm{O} / \mathrm{g}\right)$ at different temperatures : (a) 310 ;(b) 273; (c) 255; (d) 240; (e) $200 \mathrm{~K}$. Measurements are for $Q \approx 2.0 \mathrm{~A}^{-1}$. N.B.Shift in ordinates. The range of time of flight corresponds to an energy transfer, $\Delta w$ of 0 to $\approx 100 \mathrm{meV}$.

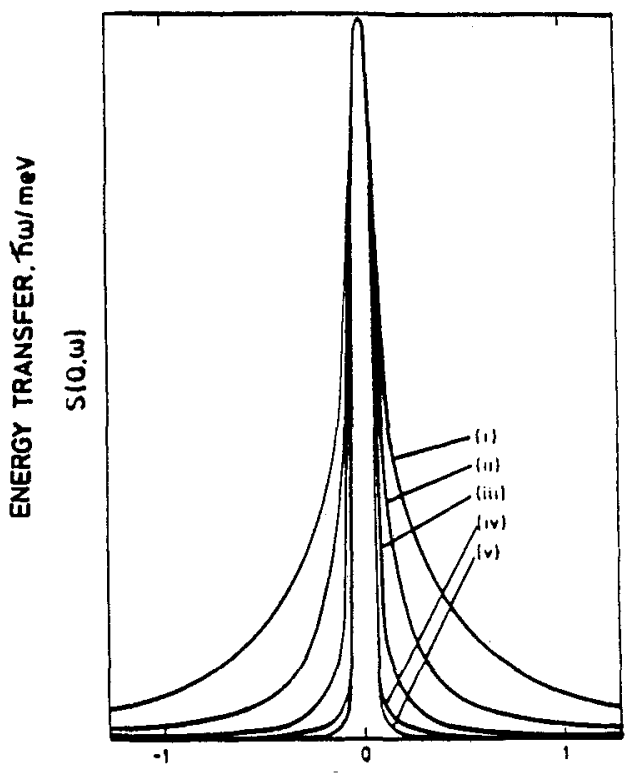

Fig. 3 : Evolution of the quasi - elastic peak with temperature for water in porous silica at different temperatures: (i) 310; (ii)273; (iii)255; (iv)240; (v) $200 \mathrm{~K} \mathrm{N.B.} \mathrm{(v)} \mathrm{is} \mathrm{identical} \mathrm{with} \mathrm{the} \mathrm{resolution}$ function. $Q \approx 1.6 \AA^{-1}$.

\section{NEUTRON DIFFRACTION OF WATER IN SILICA GELS}

Ice and bulk liquid water have a markedly different structure as depicted schematically in Fig.4(a) and (b). Ice has a characteristic hexagonal structure with $4 \mathrm{H}$-bonds per oxygen whereas the hydrogen bond structure of water is less ordered and has an average statistical number between 3 and 4 at ambient temperature and down

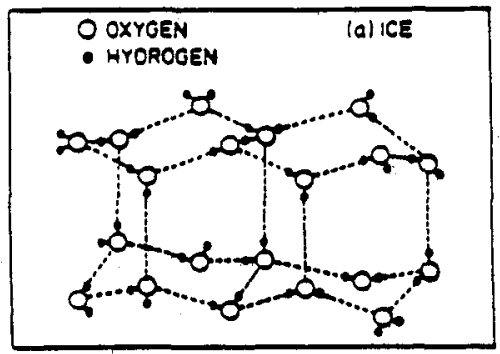

Fig.4:Diagram depicting hydrogen-bonded structure in (a) hexagonal ice and (b) liquid water.

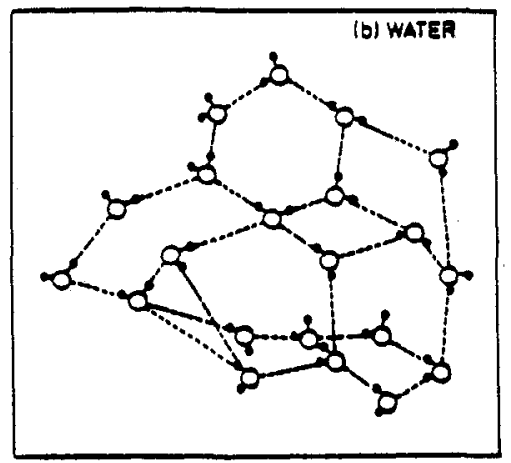



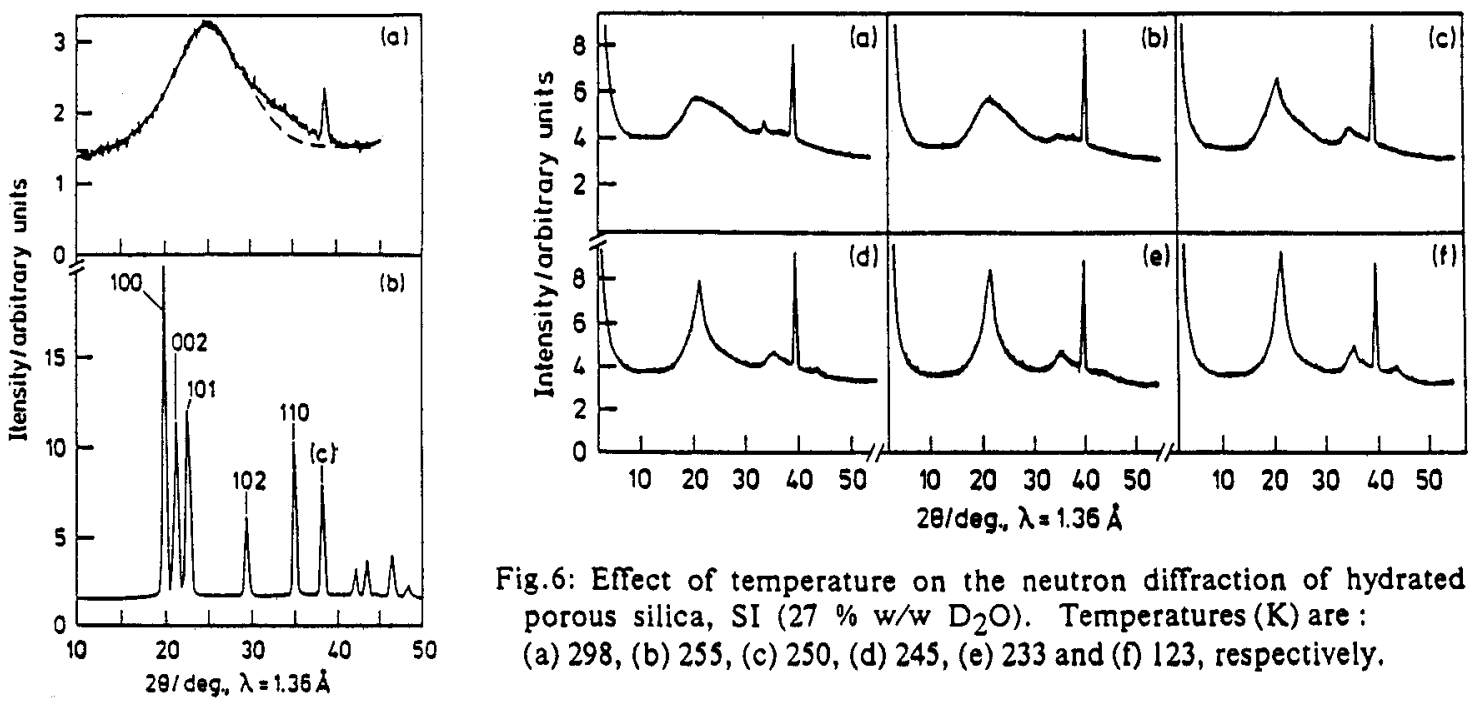

Fig.6: Effect of temperature on the neutron diffraction of hydrated porous silica, SI $\left(27 \% \mathrm{w} / \mathrm{w} \mathrm{D}_{2} \mathrm{O}\right)$. Temperatures $(\mathrm{K})$ are : (a) 298 , (b) 255 , (c) 250 , (d) 245 , (e) 233 and (f) 123 , respectively.

Fig.5: Neutron diffraction of

(a) liquid $\mathrm{D} 2 \mathrm{O}$ at $298 \mathrm{~K}$ and

(b) ice at $263 \mathrm{~K}$.

to the normal freezing point (refs. 16-17). These structural differences are reflected in the neutron diffraction of bulk water $\left(\mathrm{D}_{2} \mathrm{O}\right)$ and ice in Fig.5(a) and (b).

In mesoporous silicas the freezing of water (ice formation) occurs at temperatures considerably below $273 \mathrm{~K}$ and not at all when the pore size approaches the micropore range, $=2 \mathrm{~nm}$ (see Figure 6). For the case illustrated, a regular $\mathrm{H}$-bond network is unable to form in the confined pore space and the water remains in a supercooled vitreous state.

\section{APPLICATIONS OF SANS}

\subsection{Studies of capillary condensation and micropore filling of water in oxide gels}

SANS has recently been used in a novel approach to investigate the mechanisms of water adsorption in ceria and silica gels of different pore size $\left(\mathrm{r}_{\mathrm{p}} / \mathrm{nm}\right) ;<2 ; \approx 2.0 ; 2.9$ ) (ref.18). By using a mixture of $\mathrm{D}_{2} \mathrm{O} / \mathrm{H}_{2} \mathrm{O}$ having the same scattering length as the solid oxide phase it is possible to follow the formation of multilayer adsorption and capillary condensation within the globular packings of solid particles (see figure 7). In figure 8 , results of the uptake of water $\left(61 \% \mathrm{D}_{2} \mathrm{O}\right)$ in a mesoporous silica $\left(r_{p} \approx 2.9 \mathrm{~nm}\right)$ at progressively increasing relative vapour pressures, $\mathrm{p} / \mathrm{p}_{\mathrm{o}}$ are shown. Here we note that the contrast match condition of water with silica occurs at a composition of $61 \% \mathrm{D}_{2} \mathrm{O}$. In Fig.7(d), it will be noted that there is effectively no scattering when the pore space is saturated with water $\left(\mathrm{p} / \mathrm{p}_{0}=0.97\right)$.

These results are in accord with theoretical predictions of multilayer adsorption and capillary condensation. With microporous gels, the adsorption behaviour is different and is consistent with a volume filling process with a density of the adsorbed phase markedly less $(\approx 70 \%)$ that in bulk water.

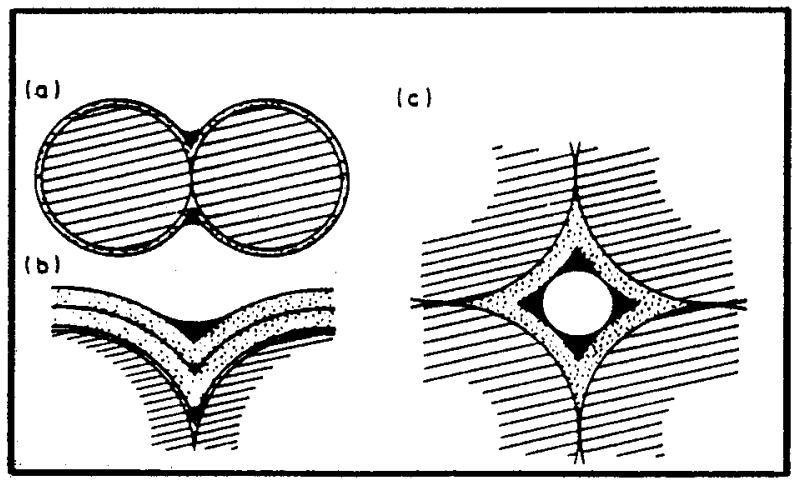

Fig. 7:Idealised depiction of adsorption and capillary condensation in sphere packings: (a) adsorbed film and annular meniscus at points of sphere contact, (b) development of contact zone on progressive adsorption, and (c) onset of menisci coalescence in a pore throat, loading to spontaneous fillings (after Kiselev et al. (ref. 19)). 


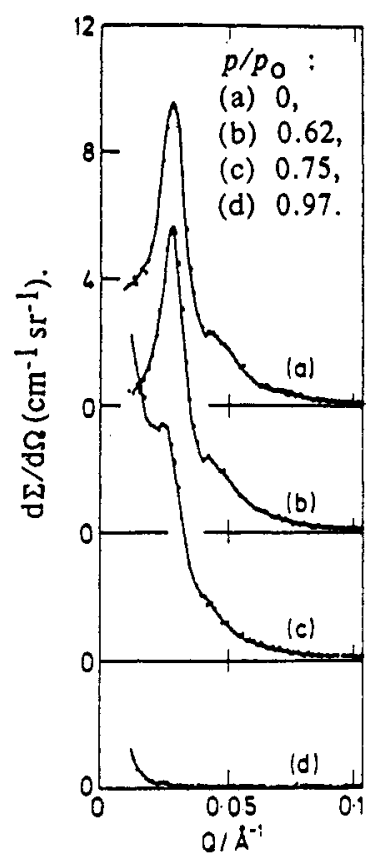
Fig.8: SANS of silica gel S4 after equilibration with water $\left(D_{2} \mathrm{O}, 61 \% \mathrm{v} / \mathrm{v}\right)$ at different relative vapor pressures.

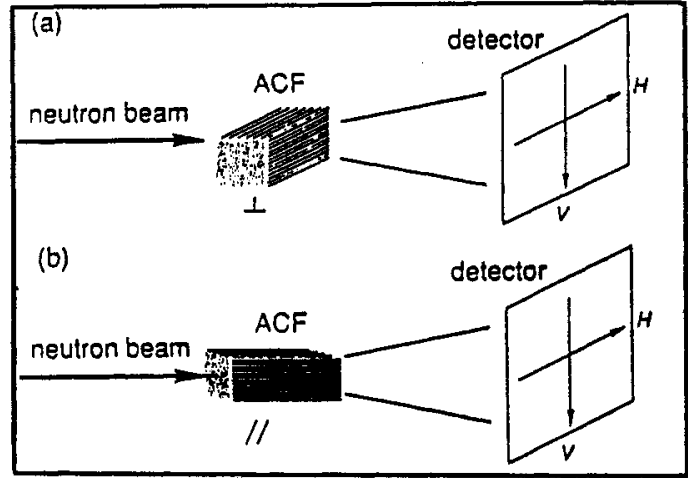

Fig.9:Orientation of ACF. (a) horizontal and (b) parallel to the incident neutron beam with respect of the two axes on the two-dimensional detector.

\subsection{Investigations of the structure of microporous carbon fibres}

The structure of micropores in activated carbon fibres (ACF) has recently been investigated by SANS (ref. 20). These pores are slit-shaped (ref.21-22) and are formed by the parallel alignment of microcrystals of graphite along the axes of the carbon fibres.

This has been established by SANS with ACF samples oriented in two different directions to the incident neutron beam (see figure 9).

Results showing SANS along the two axes of the detector for ACF samples oriented horizontally indicate that the scattering is anisotropic (figure 10).

In (i) the scattering arises from the surface of the microcrystals (>1000 $\mathrm{m}^{2} \mathrm{~g} \cdot 1$ ) which have a "smooth" surface and give a decrease in scattering of $Q^{-4}$. In (ii) the scattering arises from the edges of the microcrystals, which are "rough" and have a surface fractal dimension of $\approx 3$. (Power law of $I(Q)=Q^{-3}$ (refs. 24-25).

When the fibres are oriented with their axes parallel to the incident beam (Fig. 11), the scattering is isotropic, as can be inferred from a theoretical analysis of scattering from oriented particles (ref.23). In this situation, the scattering contribution comes from both the surfaces and edges of the microcrystals, with the former dominating. The power law component is consequently now close to $Q^{-4}$.

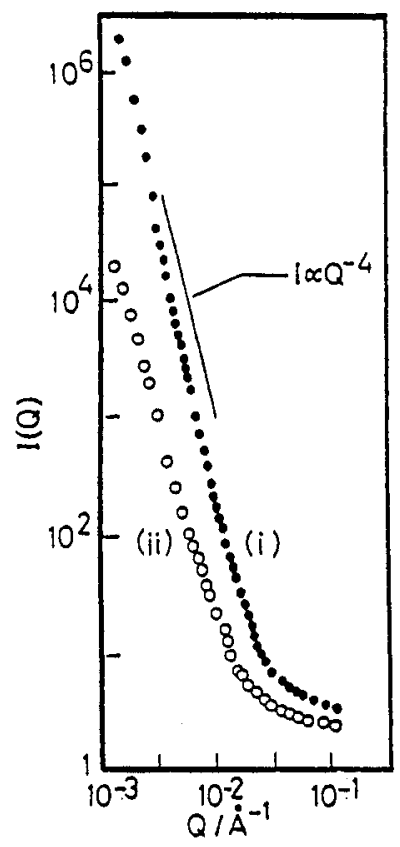

(Fig. 10: SANS of oriented ACF. Fibers are oriented horizontally with their axes perpendicular to the incident beam.

(i),SANS along the vertical axis; faces of graphite microcrystals;

(ii), along the horizontal axis of the detector. Crystal Edges-fractal. Scattering is isotropic and $I(Q)$ is radially averaged data.

Fig. Il: Fibers are oriented with their axes parallel to the incident beam. Scattering is $\longrightarrow$ isotropic and $I(Q)$ is radially averaged data.

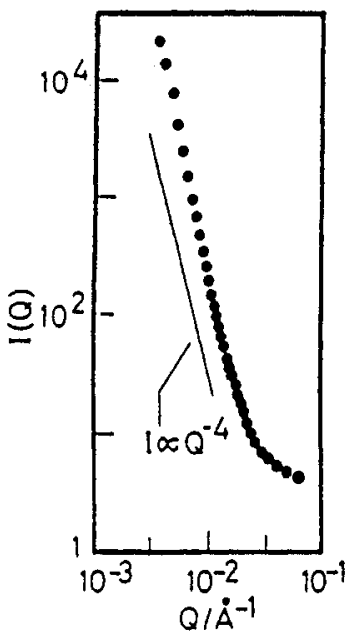




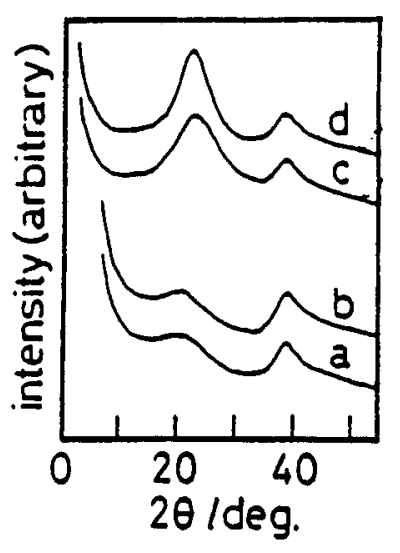

Fig. 12: Neutron diffraction of ACF

(a) initial; (b)after outgassing at $300 \mathrm{~K}$;

(c) after adsorption of $\mathrm{D}_{2} \mathrm{O}$ at $300 \mathrm{~K}$;

(d) after cooling to $123 \mathrm{~K}$.

N.B. Intensity axis is displaced for each run.

Finally we illustrate (Fig. 12) the neutron diffraction of water $\left(D_{2} O\right)$ in the supercooled condition in this $A C F$ sample under conditions of pore saturation. It will be noted that the water remains in an unfrozen vitreous state after cooling to $123 \mathrm{~K}$. Such behaviour is similar to that observed with silica gels and indicates that an ordered H-bond network as occurs in bulk crystalline ice cannot form in the confined volume of the micropores.

\section{REFERENCES}

1. J.D.F.RAMSAY, Pure and Appl. Chem., 61, 1963 - 1968 (1989).

2. J.D.F.RAMSAY and C.POINSIGNON, Langmuir, 3 , 320.326 (1987).

3. J.CONARD, H.ESTRADE-SZWARKOPF, C.POINSIGNON, A.J.DIANOUX, J.Phys., C5, 169 (1984).

4. J.D.F.RAMSAY, in Characterization of Porous Solids I, p 23-24; Eds. K.K.UNGER, J.ROUQUEROL, K.S.W.SING and H.KRAL, Elsevier, Amsterdam (1988).

5. H.REICHERT, U.MULLER, K.K.UNGER, Y.GRILLET, F.ROUQUEROL, J.ROUQUEROL and J.P.COULOMB, in Characterization of Porous Solids II, p 535.542, Eds. F.RODRIGUEZREINOSO, J.ROUQUEROL, K.S.W.SING and K.K.UNGER, Elsevier, Amsterdam (1991).

6. J.D.F.RAMSAY, Chem.Soc.Rev., 15, 335-371 (1986).

7. P.A.EGELSTAFF, An Introduction to the Liquid State, Academic Press, London (1967).

8. T.SPRINGER, Quasielastic Neutron Scattering for the Investigation of Diffusive Motions in Solids and Liquids, Springer Tracts in Modern Physics, 64, Springer-Verlag, Berlin (1972).

9. J.TEIXEIRA, M.C.BELLISENT-FUNEL, S.H.CHEN, A.J.DIANOUX, J.Phys., C7, 65 (1984).

10. J.D.F.RAMSAY, H.J.LAUTER, J.TOMPKINSON, J.Phys. C7, 73.79 (1984).

11. C.POINSIGNON and J.D.F.RAMSAY, J.Chem.Soc., Faraday Trans. 1, 82, 3447.3459 (1986).

12. W.MARS HALL and S.W.LOVESEY, Theory of Thermal Neutron Scattering, Oxford University Press, London and N.Y. (1971).

13. A.GUINIER and G.FOURNET, Small Angle Scattering of X-rays, Wiley, New York (1955).

14. B.O.BOOTH and J.D.F.RAMSAY, in Principles and Applications of Pore Structural Characterization, p97.116,Eds.J.M.HAYNES and P.ROSSI-DORIA, J.W.ARROWSMITH Ltd, Bristol (1985).

15. P.W.SCHIDT, in Characterization of Porous Solids I, p 35-48, Eds. K.K.UNGER, J.ROUQUEROL, K.S.W.SING and H.KRAL, Elsevier, Amsterdam (1988).

16. D.EISENBERG and W.KAUZMANN, The Structure and Properties of Water, Oxford University Press, Oxford (1969).

17. See e.g. Water and Aqueous Solutions, Eds. G.W.NEILSON and J.E.ENDERBY, Adam Hilger, Bristol (1986).

18. J.D.F.RAMSAY and G.WING, J.Colloid Interface Sci., 141, 475.490(1991),

19. B.G.ARISTON, A.P.KARNAUKHOV and A.V.KISELEV, Russ. J.Phys.Chem., 36, 1159 (1962).

20. A.MATSUMOTO, K.KANEKO and J.D.F.RAMSAY in Proc.of 4th International Conference on Fundamentals of Adsorption, Kyoto, Japan (1992);(to be published).

21. K.KANETO, K.YAMAGUCHI, C.ISHII, S.OSEKI, S.HAGIWARA and T.SUZUKI, Chem. Phys. Lett., 176,75 (1991).

22. K.KANETO, K.KAKEI and T.SUZUKI, Langmuir, 5 , 879 (1989).

23. J.D.F.RAMSAY, S.W.SWANTON and J.BUNCE, J.Chem.Soc., Faraday Trans., 79, $3919-3926$ (1990).

24. H.D.BALE and P.W.SCHMIDT, Phys. Rev. Lett., 53, 596 (1984).

25. J.K.KJEMS and P.SCHOFIELD, in Scaling Phenomena in Disordered Systems, P 141, Eds. R.PYNN and A.SKELTORPE, Plenum Ltd. (1985). 